\title{
Parents' experiences of having children with a significant developmental disability
}

Kearney PM, Griffin T. Between joy and sorrow: being a parent of a child with developmental disability. J Adv Nurs 2001

Jun;34:582-92.

\section{QUESTION: What are experiences of parents who have children with significant developmental disability?}

\section{Design}

Hermeneutic phenomenology.

\section{Setting}

Penrith, New South Wales, Australia.

\section{Participants}

6 parents (2 couples and 2 single mothers) of 4 children (age range 3-6 y, 3 boys and 1 girl) participated in the study. Participants were recruited from the first author's practice experience.

\section{Methods}

An initial series of individual face to face interviews with parents were conducted. Parents were asked to talk about their experiences of living with a child with a developmental disability. The couples completed subsequent joint interviews. Interviews were audiotaped and transcribed. Transcripts and contextual notes were coded and then indexed against various starting categories. Patterns in the coding system allowed for reconceptualisation of data into fewer and denser categories. Relationships between the categories were developed. Themes, patterns, and relationships were reviewed with participants to check for intent and validation.

\section{Main findings}

Parents' experiences were interpreted as dynamic moving between joy and sorrow. Contributing to parents' sorrow were the possibility of the child dying, finding out about the child's changed potential, being treated as if there was a death in the family, being left on their own by others and the healthcare system, being vulnerable, having many fears and worries, and grief. Negativity from others contributed to parents' feelings of hopelessness, despair, helplessness, and powerlessness. Contributing to parents' joy were their children not dying, the little things their children do, new perspectives following changes in beliefs and values, and becoming stronger in the face of adversity. Their children became a source of joy and inspiration. Parents were optimistic and hopeful, and defiant of their children's imposed prognoses. They showed an understanding of their children's impairments and possible functional outcomes. They reported they had learned to live without expectations, but could not function without hopes and dreams. Their joys and sorrows were held in tension and mediated by feelings of confusion, doubt, and ambiguity. Parents spoke of confusing information and advice, ambiguous prognoses, and their own observations often conflicting with information they were given. The results show the paradox of the existence of joy because of the sorrow experienced.

\section{Conclusions}

Parents not only experienced sorrow when they have a child with a disability but also a sense of joy and gratification. Clinicians working with these families need to be cognisant of this dynamic tension and can be helpful in focusing on hope rather than pathology.

Source of funding: no external funding.

For correspondence: $M$ s P M Kearney, School of Nursing, Family and Community Health, Parramatta ER 1.20 University of Western Sydney, Penrith South DC, New South Wales 1797, Australia. Fax $+61296859023$

\section{COMMENTARY}

This study by Kearney and Griffin is an interesting paper and contributes to the field through a sensitive study of a complex process of adjustment to disability. The generalisability of the results may be compromised by the small sample size and by the inability to separate out birth defects and later brain injury. However, this does not detract from the main point, which is that professionals must be aware of the resilience of parents and the joy inherent in all human life. Rejection and disability have been sadly linked for many years and the celebration of life is presented here in a model that can aid understanding. This is particularly relevant for the practicing professional because many individuals will have no personal experience of disability. The process of managing one's own feelings can interfere with the ability to really listen to the parents being helped. The emphasis on the balance between joy and sorrow, with a mechanism that describes the process, is empowering.

The method of discourse analysis is appropriate for this type of study. Parents need to be listened to and heard. The detail to which this topic was studied will allow for the themes to be clarified and for identification of the tensions as described. The process of getting to know your child is complex for parents of children with a disability. Professional input can be confusing and interfere with the naturally developing relationship. This study makes clear the responsibility of professionals to let the parents and children learn to know each other as individuals with values and rights.

It is surprising to find a study of this nature that does not refer to Joan Bicknell's work on the psychopathology of handicap. ${ }^{1}$ Her model includes the positive aspects of the adjustment process as well as describing the mourning process. It seems that in this study by Kearney and Griffin, the emphasis on the negative has dominated the service in which the author works. If the study findings influence practice, it will be worthwhile, especially because these findings should help prevent later distress as the children become adults.

Pat Frankish, M Clin Psychol Rampton Hospital Authority Retford, UK

1 Bicknell J. The psychopathology of handicap. Br J Med Psychol 1983;56:167-78. 